\title{
ASSESSMENT OF HIDDEN CURRICULUM DURING CLINICAL ROTATIONS OF YEAR 4 MBBS STUDENTS USING HIDDEN INFORMAL CURRICULUM ASSESSMENT TOOL (HICAT)
}

\author{
Ambreen Afridi', Ahsan Sethi' ${ }^{2}$, Farooq Ahmed ${ }^{3}$, Lubna Kashif ${ }^{3}$ \\ 'Department of Community Medicine, Khyber Medical College, Peshawar - Pakistan \\ ${ }^{2}$ Institute of Health Professions Education and Research, Khyber Medical University, Peshawar - Pakistan \\ ${ }^{3}$ Department of Medical Education, Khyber Medical College, Peshawar - Pakistan
}

\begin{abstract}
Objective: This study was aimed to assess the hidden curriculum for year-4 undergraduate medical students during one of their clinical rotation using Hidden Informal Curriculum Assessment Tool (HICAT).

Material and Methods: This cross-sectional survey was conducted amongst two hundred, year 4 medical students (using HICAT questionnaire ) who had undergone clinical rotation in the department of Gynecology and Obstetrics of Khyber Teaching Hospital Peshawar over a period of three months (January to march 2020).

Results: Two hundred students participated in the survey. Out of those 110 were male and 90 were female with mean age $22 \pm 1$. Highly valued items in the minds of students included positive doctor patients relaitionship, exhibiting high professional standards and exhibiting positive role modeling. The negative experience which was the commonest and also had a significant influence on the students was competition with peers, lack of confidence and experience of being disadvantaged due to gender. Males felt more disadvantaged as compared to females. Also, students belonging to rural areas felt more disadvantaged than the students of urban areas.
\end{abstract}

Conclusion: Positive doctor patient relationship, exhibiting high professional standards and positive role modelling are considered significant parts of hidden curriculum. Negative experiences included competition with peers, lack of confidence and gender discrimination.

Keywords: Hidden curriculum, Informal curriculum, HICAT tool

This article may be cited as: Afridi A, Sethi A, Ahmed F, Kashif L. Assessment of hidden curriculum during clinical rotations of year 4 MBBS students using Hidden Informal Curriculum Assessment Tool. J Med Sci 2020 October;28(4):352-355

\section{INTRODUCTION}

Hidden curriculum is defined as a set of unwritten, informal and involuntary lessons, which includes attitudes, perceptions and behaviors that students learn in medical school along with more formal aspects of education ${ }^{1}$. The students learning and their socialization to professional attitudes and behaviors, is described by the term hidden and informal curriculum, focusing on the interpersonal processes, organizational structures and culture. ${ }^{2}$ Though, not a part of formal syllabus, yet it plays an integral role in the personality development of medical students. ${ }^{3}$ Using the analogy of an iceberg- the hidden curriculum is not visualized as it is below the surface, yet it acts as a major force in the learning environment. ${ }^{4}$ Components of

\section{Correspondence}

Dr. Farooq Ahmed

Director of Medical Education Khyber Medical College,

Peshawar - Pakistan

Email: drfarooqahmed43@gmail.com

Cell: +92-313-3799901

Date received: $11-06-2020$

Date revised: $12-08-2020$

Date accepted: $10-11-2020$ this iceberg include social norms and concealed rules to survive in a system, interpersonal relationships with teachers and peers, interaction with patients and involvement in clinical settings. ${ }^{5}$ Students may encounter both positive and negative experiences, when exposed to the hidden/ informal curriculum. For example, watching a skilled clinician work with a distressed patient or being a member of a well-functioning multidisciplinary team. Conversely, the student may witness a staff member behave in a discriminatory fashion to a patient, or be made to feel unwelcome in a clinical placement. ${ }^{6}$ The hidden curriculum cannot be excluded, but it may be designed to maximize its' positive role along with the achievement and strengthening of the desired goals of the formal curriculum. However, to transform something, one must first be able to assess it. Based on our review of the medical education literature in this area, we could only find a few validated tools for measuring both the potential positive and negative aspects of the hidden/ informal curriculum. One of that, developed by Dianne Carmody, Lexie Tregonning and Paul McGurgan, is called HICAT, which comprises of 20 items targeting areas i.e. gender, background, role model and exposure to the hidden curriculum. ${ }^{7}$ Hidden curriculum, being part of the attitudes training in medical schools has 
Assessment Of Hidden Curriculum During Cinical Rotations Of Year 4 Mbbs Students Using Hidden Informal...

neither been assessed nor explicitly emphasized over in our medical schools. ${ }^{8}$ This study aims to assess the frequency of positive and negative aspects of the hidden / informal curriculum for medical students during fourth year clinical rotation using a validated tool (HICAT). Identifying these components will sensitize the faculty, curriculum implementers and policy makers to appreciate the existence, magnitude and impact of hidden curriculum in our medical schools.

\section{MATERIALS AND METHODS}

This cross-sectional survey was conducted in Khyber Teaching hospital, Peshawar amongst students of year-4 MBBS from January to March 2020 using HICAT. This tool comprises of twenty questions with Likert scale responses having ten questions regarding positive aspects of the hidden curriculum and ten responses related to the negative aspects of it. Two modifications were made to the survey tool i.e. the five-point Likert scale responses were reduced from 5 to 3 by conjoining the number 1 and 2 as 1 and no 4 and 5 as no 3. Question addressing the ethnic background of students was taken as urban vs. rural where urban was defined as students belonging to settled districts of the province and rural as students belonging to remote areas of the province. Permission was taken through Email correspondence from the originator of HICAT, Prof Paul McGurgan in the University of Western Australia. The survey was conducted during a self-directed learning session of year-4 students including only those students who have already completed their rotation in Obstetrics and Gynecology department. After the issuance of ethical approval by Institutional research and ethical review board (IREB) of KTH, an introductory session about the hidden curriculum was arranged with year-4 students. Students who had completed rotations in Gynecology and obstetrics were included in the study. Students who failed in the previous end of the year assessment were not included. After the clinical rotation ended, the survey forms were distributed amongst 215 students. Amongst these 200 forms were returned. The results of the survey forms were analyzed using SPSS version 23.

Table 1: The frequency of responses for the medical students to the 10 positive hidden curriculum items

\begin{tabular}{|c|c|c|c|c|}
\hline Question & $\mathbf{N}$ & Always & Occasionally & Never \\
\hline I have observed high professional standards in my learning environment. & 200 & $156(78 \%)$ & $24(12 \%)$ & $20(10 \%)$ \\
\hline I have observed positive patient-doctor consultations & 200 & $134(67 \%)$ & $36(18 \%)$ & $30(15 \%)$ \\
\hline I have encountered health professionals I consider were positive role models & 200 & $154(77 \%)$ & $30(15 \%)$ & $16(8 \%)$ \\
\hline I was inspired to develop my doctor-patient skills & 200 & $164(82 \%)$ & $16(8 \%)$ & $20(10 \%)$ \\
\hline I have observed health professionals dealing with complex cases in a positive manner & 200 & $124(62 \%)$ & $40(20 \%)$ & $36(18 \%)$ \\
\hline I felt supported during my placements & 200 & $128(64 \%)$ & $46(23 \%)$ & $26(13 \%)$ \\
\hline I have observed patients being treated as unique individuals & 200 & $138(69 \%)$ & $50(25 \%)$ & $12(6 \%)$ \\
\hline I have observed health professionals educating patients about their condition & 200 & $140(70 \%)$ & $26(13 \%)$ & $34(17 \%)$ \\
\hline I have witnessed health professionals going out of their way to assist colleagues & 200 & $120(60 \%)$ & $30(15 \%)$ & $50(25 \%)$ \\
\hline I have witnessed staff acknowledging their limitations & 200 & $106(53 \%)$ & $68(34 \%)$ & $26(13 \%)$ \\
\hline
\end{tabular}

Table 2: The frequency of responses for the medical students to the 10 negative hidden curriculum items

\begin{tabular}{|c|c|c|c|c|}
\hline Question & $\mathbf{N}$ & Always & Occasionally & Never \\
\hline I heard judgmental remarks about a patient in the clinical workplace & 200 & $24(12 \%)$ & $156(78 \%)$ & $20(10 \%)$ \\
\hline I needed to compete with other medical students & 200 & $134(67 \%)$ & $36(18 \%)$ & $30(15 \%)$ \\
\hline I was troubled with the experiences I encountered during my placements & 200 & $30(15 \%)$ & $154(77 \%)$ & $16(8 \%)$ \\
\hline I felt disadvantaged because of my gender & 200 & $68(34 \%)$ & $112(56 \%)$ & $20(10 \%)$ \\
\hline I have witnessed discriminatory attitudes in learning environments & 200 & $40(20 \%)$ & $124(62 \%)$ & $36(18 \%)$ \\
\hline I have encountered health professionals I consider were negative role models & 200 & $46(23 \%)$ & $128(64 \%)$ & $26(13 \%)$ \\
\hline I have felt humiliated by a supervisor & 200 & $50(25 \%)$ & $138(69 \%)$ & $12(6 \%)$ \\
\hline I felt disadvantaged because of my background & 200 & $26(13 \%)$ & $140(70 \%)$ & $34(17 \%)$ \\
\hline I have observed poor interprofessional team work & 200 & $30(15 \%)$ & $120(60 \%)$ & $50(25 \%)$ \\
\hline I was asked to undertake a task I was not confident to perform unsupervised & 200 & $68(34 \%)$ & $106(53 \%)$ & $26(13 \%)$ \\
\hline
\end{tabular}

Table 3: Demographic variables and the effect on frequency of responses to hidden curriculum:

\begin{tabular}{|c|c|c|c|}
\hline Question & Male (N=110) & Female (N=90) & P-value \\
\hline I felt disadvantaged because of my gender & 40 & 28 & $<0.001$ \\
\hline I felt disadvantaged because of my background & 16 & 10 & 0.003 \\
\hline I was troubled with the experiences I encountered during my placements & 34 & 32 & 0.004 \\
\hline
\end{tabular}


Assessment Of Hidden Curriculum During Clinical Rotations Of Year 4 Mbbs Students Using Hidden Informal...

\section{RESULTS}

Out of 200 medical students who participated in the survey 110 were males and 90 were female with mean age $22 \pm 1$. Highly valued items in the minds of students included positive doctor patients Relaitionship (82\%), exhibiting high professional standards (78\%) and exhibiting role modeling attitude (77\%). See table 1 for details. Competition with peers (67\%), lack of confidence (34\%) and gender bias towards students (34\%) was reported by students as negative aspects of hidden curriculum (see table 2 for further details). Table 3 shows that male students felt more disadvantaged by their gender $(p<0.001)$ and rural background $(p=0.003)$ than females. Females were more often troubled by the experiences they encountered $(p=0.004)$ than males during their clinical rotation.

\section{DISCUSSION}

The results obtained by this study can be seen to be useful in determining the strengths and weaknesses within an educational and health care environment for medical students. ${ }^{11}$ The HICAT included items related to positive and negative aspects of the hidden curriculum. More than two third of the students highlighted positive role modeling, doctor patient relationship , high professional standards, dealing each patient as unique individual and the role of counseling as important components of hidden curriculum. ${ }^{12}$ Similar kinds of results were shown by a study done in Iran in which it was shown that positive role modeling and high professional standards were considered as highly important constituents of the informal curriculum. ${ }^{13}$

Competition with peers was considered to be one of the negative aspects of hidden curriculum in one third of students' responses. Only one fourth of students highlighted humiliating attitude by the faculty and negative role modeling as important aspects of hidden curriculum. ${ }^{14}$ One third of students reported gender discrimination and lack of confidence during clinical performance as negative aspects of the curriculum. Males felt more discriminated because of their gender possibly because of the environment of the Obstetrics department in Muslim and local culture. A study conducted by Wilkinson revealed that about 20 to 25 percent of students experience gender discrimination during their medical training. ${ }^{15}$ The data published by Wilkinson which showed that more than two third of women and one third of men in the whole medical course experienced gender discrimination. ${ }^{16}$ The discrepancy in terms of which gender experiences the discrimination fits with the expectation that male students are more likely to experience gender discrimination during their obstetrics and gynecology rotation. Despite the fact that this gender discrimination might be expected, the HICAT quantified it in our setup. ${ }^{17,18}$ This study is limited to a single department rotation and needs to be replicated in multiple departments and multiple institutes to signify its impact.

\section{CONCLUSION}

Some of the most important positive aspects of the hidden curriculum were identified as high professional standards, positive role modeling, inspirational doctor patient relationship and counseling by the clinical faculty. Negative aspects of the curriculum highlighted in the study included competition with peers, lack of confidence during clinical performance, gender discrimination and negative role modeling by clinical faculty. Incorporating the concepts of hidden curriculum into the explicit curriculum and training the faculty as well as students about the concepts will go a long way in producing medical professionals exhibiting highest professional standards and proper attitudes during patient and students encounter.

\section{ACKNOWLEDGEMENTS}

The authors thank those students who participated in the study.

\section{REFERENCES}

1. Lawrence C, Mhlaba T, Stewart KA, Moletsane R, Gaede B, Moshabela M. Acad Med. 2018;93(4):648-56.

2. McGurgan P, Carmody D, Tregonning A. Measuring the "Iceberg"-Quantifying the hidden and informal curriculum in clinical rotations using the Hidden Informal Curriculum Assessment Tool (HICAT). MedEdPublish 2015, 5:1-18.

3. Arnold L. Assessing Professional Behavior: Yesterday, Today, and Tomorrow. Acad. Med.2002;77(1):502-15.

4. Assor A, Gordon, D. The implicit learning theory of hidden curriculum research. J Curric Stud.2008;19(4):32939.

5. Billings ME, Lazarus ME, Wenrich M, Curtis JR, Engelberg RA. The effect of the Hidden curriculum on resident burnout and cynicism. J Grad Med Educ.2011;3(4):50310.

6. Blackall G F, Melnick SA, Shoop GH, George J, Lerner $\mathrm{SM}$, Wilson PK, et al. Professionalism in medical education: The development and validation of a survey instrument to assess attitudes toward professionalism. Med Teacher.2007; 29:58-63.

7. Souto-Otero M. Learning outcomes: good, irrelevant, bad or none of the above? Journal of Education and Work.2012; 25(3): 249-258.

8. Torrance H. Assessment as learning? How the use of explicit learning objectives, assessment criteria and feedback in post-secondary education and training can come to dominate learning. Assess Educ Princ Pol Pract.2007;14(3): 281-29.

9. Brainard AHB, Heather C. Viewpoint: Learning Professionalism: A View from the Trenches.Acad Med.2007; 11(82):1010-14. Karnieli-Miller O, VuR, Holtman M, Clyman S, Inui T. Medical Students' Professionalism Narratives: A Window on the Informal and Hidden Curriculum. Acad Med.2002;85(1):124-33.

10. Birden HH, Usherwood T. "They liked it if you said you cried": how medical students perceive the teaching of professionalism. Med J Aust.2913;199(6):40-409. 
Assessment Of Hidden Curriculum During Clinical Rotations Of Year 4 Mbbs Students Using Hidden Informal...

11. Hafferty FW: Beyond curricular reform: confronting medicine's hidden curriculum. Acad Med. 1998, 73:403-7.

12. JM, Thomas EJ, Bell SK: Speaking up about the dangers of the hidden curriculum. Health Aff. 2014, 33:168-71.

13. Mahood SC: Beware the hidden curriculum. Can Fam Physician. 2011, 57:983-985.

14. Hopkins L, Saciragic L, Kim J, Posner G: The hidden curriculum: exposing the unintended lessons of medical education. Cureus. 2016, 8:845.

15. Chuang AW, Nuthalapaty FS, Casey PM, et al.To the point: reviews in medicine education - taking control of the hidden curriculum. Am J Obstet Gynecol. 2010, 203:1-6.

16. Arnold RM: Formal, informal and hidden curriculum in the clinical years: where is the problem? J Palliat Med. 2007, 10:646-648.

17. Gaufberg EH, Batalden M, Sands R, Bell SK. The hidden curriculum: what can we learn from third-year medical student narrative reflections? Acad Med. 2010, 85:170916.

18. Karnieli-Miller O, Vu R, Frankel RM, et al. Which experiences in the hidden curriculum teach students about professionalism? Acad Med. 2011, 86:369-377.

CONFLICT OF INTEREST: Authors declare no conflict of interest

GRANT SUPPORT AND FINANCIAL DISCLOSURE: NIL

\section{AUTHOR'S CONTRIBUTION}

Following authors have made substantial contributions to the manuscript as under

Afridi A: conducted the study, analyzed the data and was the lead author of the manuscript.

Sethi A: Review and supervision.

Ahmed F: helped in selecting the topic, formulating the methodology, ethical approval to conduct the study and critical review of the article.

kashif L: $\quad$ helped in collection of data and introduction of the topic to the students.

Authors agree to be accountable for all aspects of the work in ensuring that questions related to the accuracy or integrity of any part of the work are appropriately investigated and resolved.

Appendix 1: Hidden Informal Curriculum Assessment Tool (HICAT)

\begin{tabular}{|c|c|c|c|}
\hline Question & Always & Occasionally & Never \\
\hline \multicolumn{4}{|l|}{ I have encountered health professionals I consider were positive role models } \\
\hline \multicolumn{4}{|l|}{ I have observed patients being treated as unique individuals } \\
\hline \multicolumn{4}{|l|}{ I needed to compete with other medical students } \\
\hline \multicolumn{4}{|l|}{ I was asked to undertake a task I was not confident to perform unsupervised } \\
\hline \multicolumn{4}{|l|}{ I have observed poor inter professional team work } \\
\hline \multicolumn{4}{|l|}{ I was inspired to develop my doctor-patient skills } \\
\hline \multicolumn{4}{|l|}{ I heard judgmental remarks about a patient in the clinical workplace } \\
\hline \multicolumn{4}{|l|}{ I have witnessed staff acknowledging their limitations } \\
\hline \multicolumn{4}{|l|}{ I have observed positive patient-doctor consultations } \\
\hline \multicolumn{4}{|l|}{ I have witnessed discriminatory attitudes in learning environments } \\
\hline \multicolumn{4}{|l|}{ I have felt humiliated by a supervisor } \\
\hline \multicolumn{4}{|l|}{ I have encountered health professionals I consider were negative role models } \\
\hline \multicolumn{4}{|l|}{ I felt disadvantaged because of my gender } \\
\hline \multicolumn{4}{|l|}{ I felt disadvantaged because of my ethnic background } \\
\hline \multicolumn{4}{|l|}{ I was troubled with the experiences I encountered during my placements } \\
\hline \multicolumn{4}{|l|}{ I have observed health professionals educating patients about their condition } \\
\hline \multicolumn{4}{|l|}{ I have observed high professional standards in my learning environments } \\
\hline \multicolumn{4}{|l|}{ I have witnessed health professionals going out of their way to assist colleagues } \\
\hline \multicolumn{4}{|l|}{ I have observed health professionals dealing with complex cases in a positive manner } \\
\hline I felt supported during my placements & & & \\
\hline
\end{tabular}

Impact rating: List which of the three experiences from above list (1-20) that had the most impact for you during clinical rotation (these do not necessarily need to be those which you experienced most frequently).

Please use the tick box to describe how often you relate to the statements about your experience in the Hidden and informal curriculum in clinical rotations.

Options: Always: A Occasionally: B Never: C 